\title{
High oleic sunflower biodiesel: quality control and different purification methods
}

\author{
By Anna L.M.T. Pighinelli, ${ }^{a}$ Roseli A. Ferrari, ${ }^{b}$ Ana M. R. O. Miguel $^{b}$ and Kil J. Park ${ }^{a, *}$ \\ a University of Campinas (UNICAMP), P.O. Box 6011, 13083-875 Campinas-SP, Brazil. \\ ${ }^{b}$ Food Technology Institute (ITAL), Av. Brasil, 2880-P.O. Box 139 CEP 13070-178 Campinas-SP Brazil.
}

( ${ }^{\star}$ Corresponding author: annalets@ feagri.unicamp.br)

\section{RESUMEN}

Biodiesel de girasol alto oleico: calidad y diferentes métodos de purificación

El objetivo del presente trabajo es evaluar la producción de biodiesel usando etanol y aceite de girasol. La extracción del aceite de girasol fue evaluada primero. Un diseño experimental fue usado para estimar la influencia de las variables independientes: temperatura del grano $\left(25^{\circ}\right.$ a $\left.110^{\circ} \mathrm{C}\right)$ y rotación del expeller (85 a 119 rpm) en la obtención del aceite crudo. El mejor resultado obtenido fue un $68,38 \%$, conseguido con una rotación de 100 a $115 \mathrm{rpm}$, una temperatura de grano de $25^{\circ}$ a $30^{\circ} \mathrm{C}$ y un contenido de humedad de alrededor del $7 \%$. El siguiente estudio mediante transesterificación, evaluó la influencia de la relación molar etanol: aceite y concentración de catalizador (metilato sódico) en el rendimiento de la fase rica en esteres. El rendimiento más alto fue $98,39 \%$ obtenido con una relación molar de 9.1 y $3 \%$ de catalizador. Un experimento fue entonces realizado en un pequeño reactor, y el biodiesel producido fue purificado por tres métodos diferentes: agua ácida, sílica y destilación. Los aspectos de calidad de las muestras de biodiesel purificadas fueron evaluados de acuerdo a las especificaciones brasileñas para biodiesel, y la destilación mostro ser el mejor método de purificación.

PALABRAS-CLAVE: Aceite crudo - Destilación - Diseño experimental - Etanolísis - Extración mecánica de aceite - Sílica.

\section{SUMMARY}

High oleic sunflower biodiesel: quality control and different purification methods.

The objective of the present work is to evaluate the production of biodiesel using ethanol and sunflower oil. The extraction of the sunflower oil was evaluated first. An experimental design was used to estimate the influence of the independent variables grain temperature $\left(25^{\circ}\right.$ to $\left.110^{\circ} \mathrm{C}\right)$ and expeller rotation ( 85 to $119 \mathrm{rpm}$ ) on the crude oil. The best result obtained was $68.38 \%$, achieved with a rotation from 100 to $115 \mathrm{rpm}$, grain temperature ranging from $25^{\circ}$ to $30^{\circ} \mathrm{C}$ and moisture content of around $7 \%$. The next study consisted of transesterification, evaluating the influence of the ethanol, oil molar ratio and the catalyst concentration (sodium methylate) on the ester-rich phase yield. The highest yield was $98.39 \%$ obtained with a molar ratio of $9: 1$ and $3 \%$ catalyst. An experiment was then carried out on a small reactor and the biodiesel produced was purified by three different methods: acidified water, silica and distillation. The quality aspects of the purified biodiesel samples were evaluated according to the Brazilian specifications for biodiesel, and distillation was shown to be the best method of purification.

KEY-WORDS: Crude oil - Distillation - Ethanolysis Experimental design - Oil expelling - Silica.

\section{INTRODUCTION}

Biodiesel has been extensively examined due to its great importance on the global scene because it is considered to be the most suitable substitute for diesel. Biodiesel is defined as the simple alkyl monoesters of long chain fatty acids derived from renewable feedstocks. The most widely adopted process for producing biodiesel consists of a chemical reaction in which triacylglycerols react with an alcohol, using an alkaline catalyst to produce biodiesel and glycerol (Knothe, 2005).

The alcohol most commonly used to produce biodiesel is methanol due to its low cost. In countries such as Brazil, ethanol is an excellent alternative, since the country is a major world producer of ethanol. Ethanol is less toxic than methanol, which is still considered to be very toxic, even when obtained by the distillation of wood.

Despite its advantages, the ethanolysis reaction produces stable emulsions that complicate the separation of esters and purification when compared to the methanolysis reaction (Kucek et al., 2007). After the glycerol has been recovered by gravity, the biodiesel is purified, eliminating contaminants such as free glycerol, soaps, metals, alcohol and catalysts (Predojevic, 2008).

According to Cooke et al. (2003) and Berrios \& Skelton (2008), wet and dry washings are the two methods most frequently used to purify biodiesel, but the more traditional and more widely used form of removing excess contaminants from biodiesel is wet washing. The problem of including additional water to the process is the increase in cost and production time. Dry washing replaces the water with an ion exchange resin, silica or a magnesium silicate powder to neutralize the impurities. Both wet and dry washing methods are being used in industrial plants.

The high oil content of sunflower seeds favors pressing produces a high protein cake and the crop 
shows good adaptability with respect to soil and temperature, making this oilseed a good alternative for biodiesel. The production of biodiesel from sunflower involves simple procedures resulting in a high quality fuel which offsets the higher market values (Domingos et al., 2004). Pighinelli et al. (2010) evaluated the sunflower oil used as raw material for biodiesel production.

The physical extraction by crushing in a screw is based on submitting the seeds to the intense mechanical action provided by conveyer screws turning within a fixed barrel (Dufaure et al., 1999). Optimization of the oil extraction process consists of defining the optimum parameters, for example, rotation speed of the screw, grain temperature and moisture content to reach the highest oil yields (Mpagalile et al., 2006). The advantage of this technology is the low installation cost and consequently small traders can use it to process their oilseeds.

This study aimed at evaluating the influence of the temperature and screw rotation speed on the yield of crude oil as well as examining the reaction conditions such as the molar ratio (between the ethanol and vegetable oil) and the catalyst concentration used in the transesterification of the crude sunflower oil. Three purification methods were also evaluated, using current Brazilian standard biodiesel as the reference for the quality control of the biodiesel.

\section{MATERIALS AND METHODS}

\subsection{Production and processing of the raw material}

The sunflower seeds were acquired at a local market and the moisture (AOAC, 2007) and oil (AOCS, 2008 ) contents of the grains were determined.

The sunflower seeds were selected and all sorts of foreign materials or deteriorated grains that could affect the extraction of the oil were removed. Five kilograms of seeds were used in each experimental run. Heating was produced using a gas cooker system, and the temperatures were measured using an infrared thermometer (BT TIP 400, resolution $0.1^{\circ} \mathrm{C}$ ). Pressing was performed using a stainless steel expeller with a capacity to press $40 \mathrm{~kg}$ of grains per hour (ECIRTEC MPE-40). The experiments were performed in a Pilot Oil Plant at the Food Technology Institute (ITAL, Campinas, Brazil).
A $2^{2}$ factorial experimental design with 4 factorial points, 4 axial points and 2 central points was adopted to optimize the oil extraction (Barros Neto et al., 2003). Two independent variables were evaluated: press rotation $(\mathrm{R})$ and grain temperature (T).The response was summarized as oil yield. A second order mathematical model (Equation 1) was used to analyze the effects of the independent variables (1: rotation; 2: temperature) on the oil yield $(\mathrm{Y})$, using the Statistica 9.0 software. Table 1 presents the real values corresponding to the experimental design.

$$
Y=b_{0}+b_{1} x_{1}+b_{2} x_{2}+b_{11} x_{1}^{2}+b_{22} x_{2}^{2}+b_{12} x_{1} x_{2}
$$

The levels chosen for each process variable were based on preliminary studies carried out in the author's laboratory (Brossard-González et al., 2010; Pighinelli, 2010; Pighinelli et al., 2009; Pighinelli et al., 2008; Pighinelli, 2007). All 10 oil samples were filtered, homogenized and characterized, analyzing for: (a) Acid number, AOCS Ca 5a - 40 (2008), (b) Fatty acid composition, AOCS, Ce 1e - 91; Ce 1F 96; Ce 1-62 and Ce 2-66 (2008) and AOAC 996.06 (2007), (c) Moisture content and volatile matter, AOAC (2007).

\subsection{Laboratory Scale Transesterification}

Transesterification was produced using anhydrous ethanol (purity 99.5\%) and a sodium methylate solution (30\%) as the catalyst. Two independent variables were evaluated: the ethanol: oil molar ratio $(\mathrm{MR})$ and the catalyst concentration (w/w), as related to the amount of oil to be transesterified (C). The response was summarized as the ester-rich phase (BY). Table 2 presents the real values corresponding to the experimental design.

The mass of ethanol used in each experiment ranged from 4.1844 and $20.9220 \mathrm{~g}$ and was calculated according to the mean molecular mass of the oil (Equation 2).

$$
M M_{\text {oil }}=3\left[\Sigma\left(\%_{\text {f.acids }}\right)\left(M M_{\text {f.acids }}\right)\right]+M M_{g}-3\left[\left(M M_{\text {water }}\right)\right.
$$

where:

$\mathrm{MM}_{\mathrm{g}}$ : molecular mass of the glycerol;

$\mathrm{MM}_{\text {water }}$ : molecular mass of 3 water molecules, lost during formation of the triacylglycerols;

$\%_{\text {f.acids: }}$ : quantity of each fatty acid present in the oil molecule;

$\mathrm{MM}_{\text {f.acids: }}$ molecular mass of each fatty acid present in the oil molecule $(\mathrm{g} / \mathrm{mol})$;

$\mathrm{MM}_{\mathrm{oil}}$ : molecular mass of the $(\mathrm{g} / \mathrm{mol})$.

Table 1

Real values for the rotation and temperature in the experimental design for extraction of the oil

\begin{tabular}{lccccc}
\hline \multirow{2}{*}{ Variables } & \multicolumn{5}{c}{ Codified levels } \\
\cline { 2 - 6 } & $-\mathbf{1 . 4 1}$ & $\mathbf{- 1 . 0}$ & $\mathbf{0}$ & $\mathbf{1 . 0}$ & $\mathbf{1 . 4 1}$ \\
\hline Rotation $(\mathrm{rpm})$ & 85 & 90 & 102 & 114 & 119 \\
Temperature $\left({ }^{\circ} \mathrm{C}\right)$ & 25 & 30 & 42.5 & 55 & 60 \\
\hline
\end{tabular}


Table 2

Real values for the molar ratio and catalyst concentration in the experimental design for the transesterification reaction

\begin{tabular}{lccccc}
\hline \multirow{2}{*}{ Variables } & \multicolumn{5}{c}{ Codified levels } \\
\cline { 2 - 6 } & $-\mathbf{1 . 4 1}$ & $-\mathbf{1 . 0}$ & $\mathbf{0}$ & $\mathbf{1 . 0}$ & $\mathbf{1 . 4 1}$ \\
\hline Molar ratio & 3.0 & 4.7 & 9.0 & 13.3 & 15.0 \\
Catalyst conc. (\% by weight) & 1.00 & 1.58 & 3.00 & 4.42 & 5.00 \\
\hline
\end{tabular}

The molecular mass of glycerol is $92 \mathrm{~g} / \mathrm{mol}$ and the molecular mass of three water molecules is 54 $\mathrm{g} / \mathrm{mol}$. Considering Equation 2, it was possible to calculate the mass of ethanol necessary for each of the transesterification experiments for each of the ethanol: oil molar ratios used.

Initially, $25 \mathrm{~g}$ of crude sunflower oil were added to the flask, which was heated to $45^{\circ} \mathrm{C}$. In another flask, a pre-specified amount of sodium methylate was added to a predetermined amount of ethanol and the resulting solution was added to the preheated oil and stirred for 30 minutes.

The glycerin phase was recovered immediately after phase separation. The ester-rich phase was analyzed using a Waters 600E liquid chromatograph equipped with two columns in series (one $500 \AA$ and one $100 \AA$ J Jordi Gel DVB, both $300 \mathrm{~mm} \times 7.8 \mathrm{~mm}$ ), refractive index detector, 50-minute run time, injector and column temperatures of $40^{\circ} \mathrm{C}, 0.5 \mathrm{ml} / \mathrm{min}$ flow rate and sample volume of $20 \mu \mathrm{L}$. Quantification was based on external calibration using triacylglycerol, diacylglycerol, monoacylglycerol and free fatty acid standard solutions along with commercial biodiesel. The ester-rich phase samples were prepared in THF (tetrahydrofuran) to a final concentration of 1 $\mathrm{mg} / \mathrm{mL}$ (Schoenfelder, 2003).

\subsection{Reactor Transesterification}

The experimental condition corresponding to test 2 was applied to a stirred batch tank reactor. The building of the reactor was financed by the Sao Paulo State Research Foundation (FAPESP $2006 / 59907-1)$. The reactor was made of stainless steel plates with a conical bottom, 25 liter capacity and a heating system using indirect steam. Fifteen $\mathrm{kg}$ of crude sunflower oil, $3.9 \mathrm{~kg}$ of anhydrous ethanol and $0.6 \mathrm{~kg}$ of a sodium methylate solution $(30 \%)$ were used. The chemical reactions were carried out at $45^{\circ} \mathrm{C}$ for 30 minutes.

The mechanical stirrer was first set at $580 \mathrm{rpm}$ until the oil had reached the ideal temperature. After adding the catalytic solution, the rotation was decreased to $415 \mathrm{rpm}$ and maintained until the conversion into biodiesel had occurred. For the final reaction stage, the rotation was again increased to $580 \mathrm{rpm}$. Adjustment of the rotation took into account the mixing intensity required for adequate blending of the chemical reagents with the oil as evaluated visually, favoring mass transfer during the transesterification reaction and avoiding excessive air incorporation during the process.
The mixture was then left to decant for 6 hours to allow for separation of the glycerol and ester-rich phases. Any excess ethanol in the ester-rich phase was evaporated off under reduced pressure at a temperature below $60^{\circ} \mathrm{C}$. The sample obtained, containing no ethanol, was called the "unpurified biodiesel", and was subjected to purification steps, as shown in the next section.

\subsection{Purification Studies}

Three purification methods were studied to evaluate their efficiency with respect to the quality of the biodiesel. The purification yields $(\mathrm{v} \%)$ were defined as the ratio between the volume of biodiesel obtained after purification and the volume of unpurified biodiesel. The biodiesel was characterized in relation to the technical specifications for Brazilian biodiesel (Resolution 7 of the National Petroleum, Natural Gas and Bio-fuels, ANP, dated March, 2008), using the following methods: ABNT NBR 7148 for specific gravity at $20^{\circ} \mathrm{C}\left(\mathrm{kg} / \mathrm{m}^{3}\right)$, ASTM D 6304 for water content $(\mathrm{mg} / \mathrm{kg})$, ABNT NBR 14598 for flash point $\left({ }^{\circ} \mathrm{C}\right)$, ASTM D 6584 for total glycerin content $(\mathrm{w} \%)$, free glycerin content $(\mathrm{w} \%)$ and acylglyceride content (w\%), ASTM D 6371 for the cold filter plugging point $\left({ }^{\circ} \mathrm{C}\right)$, ASTM D 4530 for the carbon residue (w\%), EN ISO12662 for total contamination (w\%), EN 14103 for total ester content (w\%), EN 14110 for the ethanol content (w\%), ASTM D 1298/4052 for the kinematic viscosity at $40^{\circ} \mathrm{C}\left(\mathrm{mm}^{2} / \mathrm{s}\right)$, ASTM D874 for the sulfated ash content (w\%), ASTM D4294/5453 for the total sulfur content (w\%), ASTM D664 for the acid number (mg KOH/g), visual aspect, EN 14538 for the calcium, magnesium, sodium and potassium contents, EN 14107 for the phosphorous content, EN 14111 for the iodine number and EN 14112 for oxidative stability (ANP, 2010).

The first purification method consisted of washing the biodiesel with 3 liters of a $5 \%-w / w$ solution of hydrochloric acid (37\%), heated to $90^{\circ} \mathrm{C}$ (Ferrari et al., 2005). The second purification method was a technique called "dry washing", using $2 \%$ by weight of silica (GRACE DAVISON TRISYL $® 300 B \quad 97 \%$ ) and $1.6 \%$ by weight of an auxiliary filter (Celite ${ }^{\mathrm{TM}}$ ) in relation to the unpurified biodiesel mass. Purification was carried out at $90^{\circ} \mathrm{C}$ with mechanical stirring and reduced pressure for 30 minutes. Distillation was the last purification method evaluated. A flask was adapted to a bath and fitted with a reflux condenser, using a pressure of $680 \mathrm{mmHg}$. 


\section{RESULTS AND DISCUSSION}

\subsection{Raw Material Processing}

The moisture content of the seeds was $7.5 \%$ and the lipid content $46.8 \%$. The oil mass obtained in the different pressing trials varied from $51.7 \%$ to $68.4 \%$, as shown in Table 3 . The best result was associated with test number 3 , in which the rotation was set at $114 \mathrm{rpm}$ and the temperature at $30.0^{\circ} \mathrm{C}$. In contrast, the lowest oil mass obtained corresponded to test number 5 , where the rotation was set at $85 \mathrm{rpm}$ and the temperature at $42 \cdot 5^{\circ} \mathrm{C}$.

Table 3

Average oil yield for sunflower seed pressing based on a $2^{2}$ factorial experimental design, with four axial and factorial points and two central points

\begin{tabular}{cccc}
\hline Test & \multicolumn{2}{c}{ Variables } & Oil yield \\
\cline { 2 - 3 } & $\begin{array}{c}\text { Press speed } \\
(\mathbf{r p m})\end{array}$ & $\begin{array}{c}\text { Temperature } \\
\left({ }^{\circ} \mathrm{C}\right)\end{array}$ & 54.8 \\
\hline 1 & $90(-1)$ & $30.0(-1)$ & 61.5 \\
2 & $90(-1)$ & $55.0(+1)$ & 68.4 \\
3 & $114(-1)$ & $30.0(-1)$ & 64.4 \\
4 & $114(+1)$ & $55.0(+1)$ & 51.7 \\
5 & $85(-1.41)$ & $42.5(0)$ & 62.7 \\
6 & $119(+1.41)$ & $42.5(0)$ & 61.1 \\
7 & $102(0)$ & $25.0(-1.41)$ & 64.9 \\
8 & $102(0)$ & $60.0(+1.41)$ & 68.0 \\
9 & $102(0)$ & $42.5(0)$ & 66.1 \\
10 & $102(0)$ & $42.5(0)$ & \\
\hline
\end{tabular}

These results indicated a clear tendency to increase the oil mass obtained by reducing temperature and increasing rotation. No papers were found in the specialized literature in which the influences of the rotation speed and temperature on the oil yield were studied.

To verify the effect of each variable on the response evaluated, oil extraction was optimized using the Statistica 9.0 software. The same codified model shown in Equation 1 was applied to the experimental data corresponding to the transesterification reaction. The factors evaluated were molar ratio and catalyst concentration. Table 4 shows the fitting of the coefficients of the experimental data to the mathematical model, as represented by Equation (1).

The results showed in Table 4 show that the coefficients $b_{o}, b_{1}$ and $b_{11}$ were considered statistically significant at the $90 \%$ confidence level. This implied that, of the variables considered in this study, only the pressing rotation showed a statistically significant effect on the oil mass in the interval considered. The positive value of the coefficient $b_{1}$ indicated that the oil mass showed a tendency to increase with an increase in rotation speed, regardless of the temperature of the seeds. Based on these results, the codified mathematical model representing the oil extraction (Equation (1)) can be reduced to a quadratic model, containing a three-parameter equation (2).

$$
\text { OY }=65.3410+7.9824 R-7.3836 R^{2}
$$

The variance analysis was applied to verify the validity of the model represented by Equation (2). The results are presented in Table 5. The results of the variance analysis associated with the mass of oil expelled indicate that the $F$ value between the regression and the residues was almost 4 times higher than the $\mathrm{F}$ value shown in the table. The results also show that the calculated $F$ value was about 12 times less than the values displayed in the table for the lack of fit and pure error.

Table 4

Regression coefficients associated with the codified mathematical models for oil extraction

\begin{tabular}{cccc}
\hline $\begin{array}{c}\text { Regression } \\
\text { coefficient }\end{array}$ & Effect & $\begin{array}{c}\text { Standard } \\
\text { deviation }\end{array}$ & $\mathbf{P}$ \\
\hline $\mathrm{b}_{0}$ & 67.0720 & 0.9574 & 0.0091 \\
$\mathrm{~b}_{1}$ & 8.0366 & 0.9589 & 0.0756 \\
$\mathrm{~b}_{11}$ & -8.8110 & 1.2714 & 0.09123 \\
$\mathrm{~b}_{2}$ & 2.0068 & 0.9589 & 0.2838 \\
$\mathrm{~b}_{22}$ & -3.0106 & 1.2714 & 0.2544 \\
$\mathrm{~b}_{12}$ & -5.3617 & 1.3540 & 0.1675 \\
\hline
\end{tabular}

Values marked in italics are statistically significant coefficients at a level of $90 \%$. b: regression coefficient. 1: linear effect of the rotation. 2: linear effect of the temperature. 11: quadratic effect of the rotation. 22: quadratic effect of the temperature. 12: interaction effect between $R$ and $T$.

Table 5

Analysis of variance (ANOVA) for the response (oil expression) associated with the reduced and codified mathematical models, at a significant level of $90 \%$

\begin{tabular}{lcccccc}
\hline \multicolumn{1}{c}{ Source of variation } & $\mathbf{d f}$ & $\mathbf{S S q}$ & $\mathbf{M S}$ & $\mathbf{F}_{\text {calc }}$ & $\mathbf{F}_{\text {tab }}$ & $\mathbf{R}^{2}$ \\
\hline Regression & 2 & 207.0 & 104.0 & 12.20 & 3.26 & 0.78 \\
Residues & 7 & 59.5 & 8.5 & - & - & - \\
Lack of fit & 6 & 57.6 & 9.6 & 5.24 & 58.20 & - \\
Pure error & 1 & 1.8 & 1.8 & - & - & - \\
Total & 9 & 267.0 & - & - & - & - \\
\hline
\end{tabular}


These results, associated with the high correlation factor $\left(R^{2}=0.78\right)$, indicate that the model proposed represented the experimental data well. The mean absolute deviation, referring to the oil expression obtained from Equation (2) and related to the experimental data, was $7.3 \%$.

When considering the valid variance analysis associated with the high correlation values and the low absolute average deviation values, the mathematical models generated explaining the oil expression extraction can be considered valid for the rotation intervals and seed temperatures studied. Thus Equation (2) was used to generate a response surface related to the oil expression extraction, as presented in Figure 1.

It can be seen in Figure 1 that the rotation had an effect on the oil yield in the range studied. Rotation between 105 and 110 rpm gave a better oil yield, regardless of the seed temperature used.

A comprehensive analysis of all the experimental designs used for pressing sunflower seeds allowed one to define the ranges for each of the operational variables. With respect to rotation for example, sunflower seeds require higher speeds than peanut and cottonseed, requiring a range from 100 to $115 \mathrm{rpm}$. This difference can be explained according to the seed geometry and the absence of a significant abrasive element, such as the peanut shells and cottonseed linter (Pighinelli, 2010). During these studies, it could be observed that the operation was best conducted at higher speeds, allowing for a shorter pressing time. Temperatures close to room temperature were more suitable (25 and $30^{\circ} \mathrm{C}$ ), also allowing for a saving of the energy involved in the process.

The acid number of crude sunflower oil was 2.8 $\mathrm{mg} \mathrm{KOH} / \mathrm{g}$ and the moisture content and volatile matter were each $0.04 \%$. The triacylglycerides (TAGs) found in this oil contained 3.6\% palmitic acid

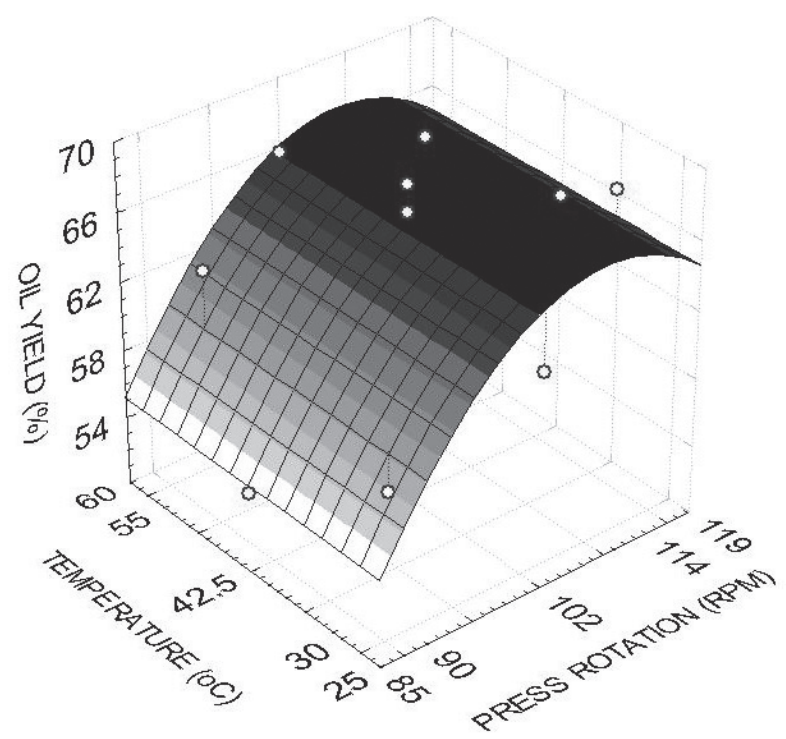

Figure 1

Response surface showing the effects of temperature and rotation on oil extraction.
(16:0), 3.2\% stearic acid (18:0), $78.8 \%$ oleic acid (18:1), 12.5\% linoleic acid (18:2), 0.1\% linolenic acid (18:3), 0.3\% arachidic acid (20:0), 0.9\% behenic acid (22:0) and $0.4 \%$ lignoceric acid (24:0) as their main fatty acid components. The sunflower seeds used were of the high oleic acid type, as can be seen from the fatty acid composition.

\subsection{Laboratory Scale Transesterification}

The ester-rich phase mass obtained in the different trials varied from $79.2 \%$ to $100.2 \%$ (Table $6)$. In the samples produced with high ethanol concentrations (ethanol:oil molar ratios of 13.3:1 and 15:1) no phase separation occurred and the whole sample (ester-rich phase + glycerol) was examined by HPSEC. Sample number 6 showed a yield above $100 \%$, confirming the presence of other alcohol-miscible components in the sample. Thus excluding this point from the experimental design, the optimal conditions corresponded to an ethanol: oil molar ratio of 9:1, which corresponds to an excess of 6 moles of alcohol and a catalyst concentration of $3 \%$. Kucek et al. (2007) and Domingos et al. (2008) studied the ethanolysis of refined soybean oil and of Raphanus sativus oil, achieving purified biodiesel yields of $95.5 \%$ and $97.1 \%$, respectively for the same molar ratio.

As expected, a tendency for the mass of biodiesel to increase with an increase in the molar ratio was observed. Table 7 shows the fitting of the coefficients to the experimental data.

The results shown in Table 7 demonstrate that all the coefficients were considered to be statistically significant at a $90 \%$ confidence level. The positive sign of both coefficients indicated that the mass of the ester-rich phase showed a

Table 6

Average yield of ester-rich phase in the transesterification on a laboratory scale, based on a $2^{2}$ factorial experimental design, with four axial and factorial points and three central points

\begin{tabular}{cccc}
\hline & \multicolumn{2}{c}{ Variables } & \multicolumn{1}{c}{$\begin{array}{c}\text { Ester-rich } \\
\text { phase (wt\%) }\end{array}$} \\
\cline { 2 - 3 } & Molar ratio & $\begin{array}{c}\text { Catalyst } \\
\text { conc. (wt\%) }\end{array}$ & \\
\hline 1 & $4.7(-1)$ & $1.58(-1)$ & 79.2 \\
2 & $4.7(-1)$ & $4.42(+1)$ & 95.5 \\
3 & $13.3(+1)$ & $1.58(-1)$ & 93.9 \\
4 & $13.3(+1)$ & $4.42(+1)$ & 91.4 \\
5 & $3.0(-1.41)$ & $3.00(0)$ & 83.7 \\
6 & $15.0(+1.41)$ & $3.00(0)$ & 100.2 \\
7 & $9.0(0)$ & $1.00(-1.41)$ & 85.2 \\
8 & $9.0(0)$ & $5.00(+1.41)$ & 96.3 \\
9 & $9.0(0)$ & $3.00(0)$ & 97.7 \\
10 & $9.0(0)$ & $3.00(0)$ & 97.2 \\
11 & $9.0(0)$ & $3.00(0)$ & 98.4 \\
\hline
\end{tabular}


Table 7

Regression coefficients associated with the codified mathematical models for biodiesel transesterification

\begin{tabular}{crcc}
\hline $\begin{array}{c}\text { Regression } \\
\text { coefficient }\end{array}$ & Effect & $\begin{array}{c}\text { Standard } \\
\text { deviation }\end{array}$ & $\mathbf{P}$ \\
\hline $\mathrm{b}_{0}$ & 97.7685 & 0.3474 & 0.0000 \\
$\mathrm{~b}_{1}$ & 8.4735 & 0.4262 & 0.0025 \\
$\mathrm{~b}_{11}$ & -6.5055 & 0.5085 & 0.0061 \\
$\mathrm{~b}_{2}$ & 7.3948 & 0.4262 & 0.0033 \\
$\mathrm{~b}_{22}$ & -7.7227 & 0.5085 & 0.0043 \\
$\mathrm{~b}_{12}$ & -9.3700 & 0.6018 & 0.0041 \\
\hline
\end{tabular}

Values marked in italics are statistically significant coefficients at a level of $90 \%$. b: regression coefficient. 1: linear effect of the molar ratio. 2: linear effect of the catalyst concentration. 11: quadratic effect of the molar ratio. 22: quadratic effect of the catalyst concentration. 12: interaction effect between MR and C.

tendency to increase as the molar ratio and catalyst concentration increased.

The interactions were analyzed separately as shown in Figure 2. As can be seen from the interactions graph, at a low catalyst concentration $(1.58 \%)$, the yield of ester-rich phase increased with an increase in the molar ratio. At the central point, there was an increase of approximately $10 \%$ when the molar ratio increased from 3 to 9 , the increase being less significant $(2.5 \%)$ when the ratio increased from 9 to 15 . At a catalyst concentration of $4.42 \%$ there was an increase in yield of the ester-rich phase (of close to $5 \%$ ), when the molar ratio increased from 13.3 to 4.7.

Based on these results, the codified mathematical model representing biodiesel production on a laboratory scale (Equation (1)) can be reduced to a quadratic model containing six parameters (Equation (3)).

$$
\begin{gathered}
B Y=97.7685+8.4735 M R-6.5055 M R^{2}+ \\
+7.3948 C-7.7227 C^{2}-9.3700 M R C
\end{gathered}
$$

The variance analysis was carried out to verify the validity of the model represented in Equation (3), and the results are presented in Table 8 . The results of the variance analysis, associated with the production of biodiesel, indicate that the $F$ value for the regression and the residues was almost 3.5 times higher than the $\mathrm{F}$ value shown in the table.

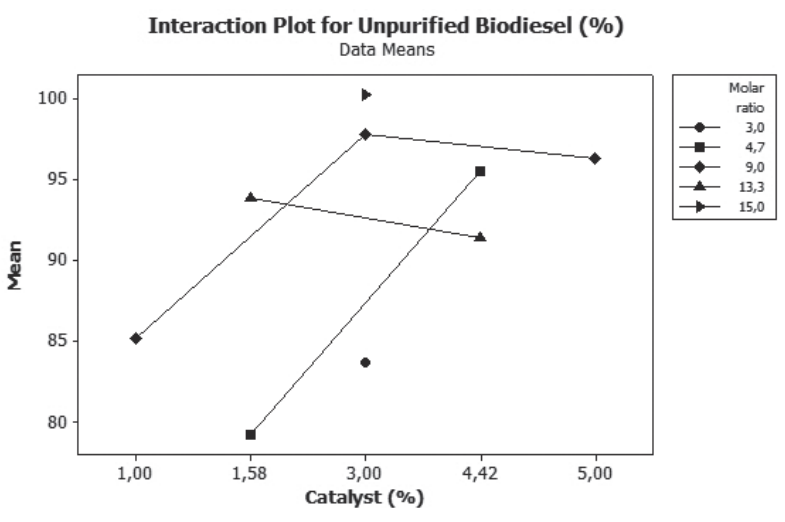

Figure 2

Interaction effects between catalyst concentration and molar ratio for the production of biodiesel.

The results also show that the calculated $F$ value was very close to the tabulated value for the lack of fit and pure error.

These results associated with the high correlation factor $\left(R^{2}=0.95\right)$ indicated that the proposed model represented the experimental data well. The mean absolute deviation obtained from Equation (3) for the production of biodiesel, as compared to the experimental data, was $6.2 \%$.

Considering the results of the variance analysis associated with the high correlation values and the low values for absolute average deviation, the mathematical model generated to explain biodiesel production can be considered valid for the molar ratio intervals and catalyst concentrations studied. Thus equation (3) was used to generate the response surface for biodiesel production in the laboratory, as presented in Figure 3.

The curvature of the response surface shown in Figure 3 demonstrated a tendency for an optimal point located in regions with a high molar ratio and intermediate catalyst concentration.

Georgogianni et al. (2008) evaluated the ethyl transesterification of crude sunflower oil (acid number of $1 \mathrm{mg} \mathrm{KOH} / \mathrm{g}$ ), using a sodium hydroxide catalyst. In this study, the influence of the catalyst concentration (1, 1.5 and $2 \%$ ) on the biodiesel yield was evaluated. After 30 minutes, the biodiesel yield was 56,67 and $78 \%$ for catalyst concentrations of 1,2 and $1.5 \%$, respectively. After 60 minutes, the maximum yields were $85 \%$ for reactions carried out with $2 \% \mathrm{NaOH}$, indicating that the catalyst

Table 8

Analysis of variance associated with the reduced and codified mathematical models, corresponding to biodiesel production, evaluated at $90 \%$ of confidence

\begin{tabular}{lcccccc}
\hline \multicolumn{1}{c}{ Source of variation } & $\mathbf{d f}$ & $\mathbf{S S q}$ & $\mathbf{M S}$ & $\mathbf{F}_{\text {calc }}$ & $\mathbf{F}_{\text {tab }}$ & $\mathbf{R}^{2}$ \\
\hline Regression & 5 & 451.0 & 90.2 & 17.79 & 5.05 & 0.95 \\
Residues & 4 & 25.4 & 5.1 & - & - & - \\
Lack of fit & 3 & 24.6 & 8.2 & 22.68 & 19.16 & - \\
Pure error & 2 & 0.7 & 0.4 & - & - & - \\
Total & 10 & 477.0 & - & - & - & - \\
\hline
\end{tabular}




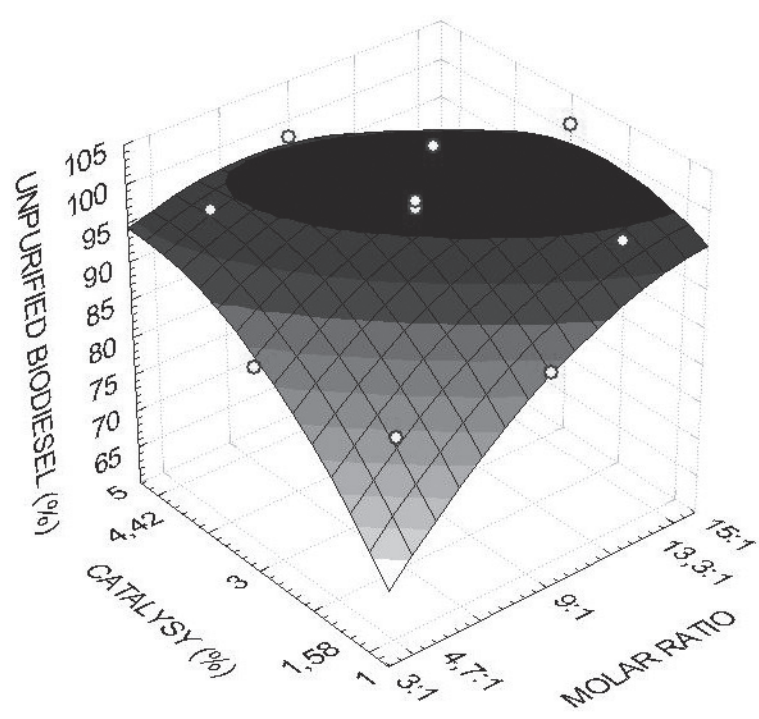

Figure 3

Response surface showing the effects of catalyst concentration and molar ratio on the production of biodiesel.

concentration had a positive effect for the molar ratio used.

The effects of the methanol, oil molar ratio (from $3: 1$ to $18: 1)$, catalyst concentration $(0,0.25 \%$, $0.50 \%, 0.75 \%, 1.00 \%, 1.25 \%$ and $1.50 \%$ ) and type $\left(\mathrm{NaOH}, \mathrm{KOH}, \mathrm{NaOCH}_{3}\right.$ and $\left.\mathrm{KOCH}_{3}\right)$ as well as reaction temperature $\left(60,45\right.$ and $\left.30^{\circ} \mathrm{C}\right)$ on the yield of sunflower biodiesel, were studied by Rashid et al. (2008). For a molar ratio of 6:1 (methanol:oil), $1 \%$ of $\mathrm{NaOCH}_{3}$ and 120 minutes of reaction, a yield of $97.1 \%$ biodiesel was obtained at a temperature of $60^{\circ} \mathrm{C}$. It was found that catalyst concentrations above $1.25 \%$ affected the quality and yield of the biodiesel produced. The best molar ratio was 6:1 (methanol:oil) for reactions carried out at $60^{\circ} \mathrm{C}$ with $1 \% \mathrm{NaOH}$ and $600 \mathrm{rpm}$. It was observed that an increase in molar ratio to above 6:1 did not cause an increase in biodiesel yield.

A similar statistical analysis was carried out by Jeong et al. (2009) to evaluate the effects of the molar ratio and catalyst concentration on animal fat transesterification. The catalyst range evaluated was from 0.16 to $1.84 \%$ and the range of methanol:fat molar ratio was from 3.48 to 8.52 . For a confidence level of $90 \%$, both factors were significant according to this study. The authors have found that the catalyst concentration had a positive linear effect, and the square of the catalyst, a negative effect. Although the molar ratio had a positive linear effect, the effects of the square of the ratio and the interaction effects were not significant.

\subsection{Reactor Transesterification}

The conditions used for test 2 (laboratory scale) with the batch reactor were a molar ratio of $4.7: 1$ (ethanol:oil) and a catalyst concentration of $4.42 \%$ of the weight of oil used. After evaporating off all the ethanol from the ester-rich phase, the presence of a large amount of soap was observed, different from the one observed during the reactions carried out on a laboratory scale. Soap formation is inevitable when this kind of catalyst is used for alcoholysis. The catalyst acts as a strong emulsifier and the accumulation of soap usually leads to lower reaction yields and greater technical difficulties in obtaining good phase separation. Therefore, the concentration of the alkali catalyst should be reduced as much as possible, as well as the amount of water present in the chemical reactants (Domingos et al., 2008).

\subsection{Purification}

Biodiesel samples produced in the reactor were purified in the laboratory. The washing of the biodiesel was highly affected by the presence of soaps in the crude biodiesel and a lot of acid water was necessary to neutralize the sample and remove the contaminants. Three-point-one liters of liquid effluents were generated and the yield using this purification technique was $84.2 \%$. The yield from the "dry washing" method was almost the same as that from wet washing, $84.6 \%$, but it had the advantage of not generating any liquid effluents. The distillation method showed the highest yield of purified biodiesel: $92.3 \%$ and all the purification methods were very efficient in removing the soaps and other contaminants.

\subsection{Biodiesel characterization}

All the biodiesel samples presented a clean aspect and Table 9 shows their characterizations.

The density of biodiesel is strongly linked to its molecular structure, such that an increase in size of the carbon chain of the alkyl ester increases its density.

The density decreased at higher oil unsaturation levels and another factor that influenced the density was the presence of impurities (Lôbo et al., 2009). The results showed that the specific gravities of all the samples were very close; indicating that this characteristic influenced the molecular structure of the oil from which the biodiesel was derived. The values obtained were within the ANP specifications. Pereyra-Irujo et al. (2009) found values close to those reported for biodiesel made from high oleic acid sunflower varieties.

The presence of residual soaps, unreacted glycerides and oxidative degradation products increased the viscosity of the biodiesel (Lôbo et al., 2009). From the results, it was expected that the biodiesel samples purified with water and with silica would present the highest values for viscosity, since the sum of the unreacted glycerides for these samples was 3.54 and $3.30 \%$, respectively. The distilled sample showed the lowest viscosity, consistent with the smaller percent of unreacted glycerides, of $0.82 \%$.

All the samples showed viscosity values within the range stipulated by the Brazilian standards. 
Table 9

Specification parameters for crude sunflower oil ethyl esters

\begin{tabular}{|c|c|c|c|c|}
\hline Parameter & Water & Silica & Distillation & ANP Limit \\
\hline Density at $20^{\circ} \mathrm{C}\left(\mathrm{kg} / \mathrm{m}^{3}\right)$ & 873.5 & 873 & 870 & $850-900$ \\
\hline Kinematic viscosity at $40^{\circ} \mathrm{C}\left(\mathrm{mm}^{2} / \mathrm{s}\right)$ & 5.3 & 5.3 & 5.0 & $3.0-6.0$ \\
\hline Water content (ppm) & 1260.3 & 788.3 & 566.2 & 500 \\
\hline Total contamination $(\mathrm{mg} / \mathrm{kg})$ & 0.8 & 4 & 6.8 & 24 \\
\hline Minimum flash point $\left({ }^{\circ} \mathrm{C}\right)$ & 165.6 & 101.6 & 49.6 & 100.0 \\
\hline Minimum ester yield (\%) & 97.2 & 98.3 & 99.3 & 96.5 \\
\hline Carbon residue (\% w/w) & 0.02 & 0.05 & 0.01 & 0.05 \\
\hline Ash content $(\% \mathrm{w} / \mathrm{w})$ & 0.02 & n.d. & 0.01 & 0.02 \\
\hline Sulphur (mg/kg) & 3.1 & 3.1 & 3.8 & 50 \\
\hline Sodium + Potassium (mg/kg) & 2.8 & 10.1 & 1.7 & 5 \\
\hline Calcium + Magnesium (mg/kg) & 1.8 & n.d. & n.d. & 5 \\
\hline Phosphorus (mg/kg) & n.d. & n.d. & n.d. & 10 \\
\hline Copper corrosion, $3 \mathrm{~h}$ at $50^{\circ} \mathrm{C}$ & 1 & 1 & 1 & 1 \\
\hline Cold filter plugging point $\left({ }^{\circ} \mathrm{C}\right)$ & -9 & -2 & -11 & 19 \\
\hline Acid value $(\mathrm{mg} \mathrm{KOH} / \mathrm{g})$ & 3.10 & 0.93 & 0.30 & 0.50 \\
\hline Free glycerol (\% w/w) & n.d. & n.d. & 0.02 & 0.02 \\
\hline Total glycerol (\% w/w) & 0.70 & 0.71 & 0.16 & 0.25 \\
\hline Monoacylglycerides (\% w/w) & 2.53 & 2.52 & 0.40 & Report \\
\hline Diacylglycerides (\% w/w) & 0.27 & 0.30 & 0.14 & Report \\
\hline Triacylglycerides (\% w/w) & 0.04 & 0.04 & 0.12 & Report \\
\hline Ethanol (\% w/w) & 0.02 & 0.02 & 0.07 & 0.20 \\
\hline Iodine value $(\mathrm{g} / 100 \mathrm{~g})$ & 89.3 & 88.8 & 96.6 & Report \\
\hline Oxidative stability at $110^{\circ} \mathrm{C}(\mathrm{h})$ & 1.3 & 2.4 & $<1$ & 6 \\
\hline
\end{tabular}

n.d.: not detected.

According to the literature, the viscosity determined for the biodiesel obtained from sunflower oil was $4.90 \mathrm{~mm}^{2} / \mathrm{s}$ (Rashid et al., 2008). The reaction conditions used by those authors were different from those employed in the present study (catalyst type and concentration, temperature and reaction time, initial raw material conditions), especially with respect to the methanol:oil molar ratio, which was $6: 1$, while for the present study it was $4.7: 1$. Since the transesterification reaction was more complete, the glyceride levels decreased and hence the viscosity also decreased.

The water content of the samples exceeded the limit stipulated by the Brazilian legislation, and the same results were observed for biodiesel from peanut and soybean oils (Pighinelli, 2010). The water may have originated from the transesterification reaction, coming from the ethanol or catalyst, or may have occurred during storage and handling. The presence of water is not desirable, since it promotes hydrolysis of the biodiesel resulting in the production of free fatty acids and also because it allows for microbial proliferation (Lôbo et al., 2009).
Distillation was the purification method which produced biodiesel with the lowest water content. This was expected, since the combination of vacuum with high temperature favors elimination of the water, but nevertheless the content was higher than expected, possibly caused by an inefficient condenser system. It was expected that purification with silica would result in a biodiesel sample containing a lot of water. The water content could be minimized by drying the biodiesel samples under vacuum to remove any excess water.

The sample purified with acidified water was filtered through anhydrous sodium sulfate after purification, but this filtration step was not enough to remove all the water. Once again the recommendation was made to dry the biodiesel under vacuum to the level stipulated by the legislation. The use of vacuum avoids the use of high temperatures which, in combination with oxygen, would degrade the sample.

The carbon residue is an index related to the contaminants present in the sample and thus to the total contamination. The contaminants that might be present are free fatty acids, free glycerol, 
total glycerol, mono, di and triacylglycerols. An evaluation of the sum of the contaminants showed that the samples purified with water and with silica contained $3.54 \%$ and $3.30 \%$, respectively, with carbon residues of 0.02 and $0.05 \%$. The distilled sample showed $0.85 \%$ contaminants and a carbon residue of $0.01 \%$.

Ash was detected in the samples purified by distillation and with water, but the values were within the ANP specifications. Rashid et al. (2008) found an ash content of $0.010 \%$ and $0.012 \%$ of sulfur. The presence of sulfur was related to the origin of the raw material, and the values observed were similar, regardless of the purification method used. The presence of sodium was strongly related to the type of catalyst used, indicating that the silica purification method was not sufficiently efficient to remove it.

The cold filter plugging point increased as the presence of saturated fatty acids in the biodiesel increased. A joint analysis of the cold filter plugging point temperatures and the iodine value corroborated this assertion. The distilled sample showed the highest iodine value and hence the lowest cold filters plugging point temperature. According to the literature, Rashid et al. (2008) found a cold filter plugging point of $-1^{\circ} \mathrm{C}$ for biodiesel produced from sunflower oil, rich in linoleic fatty acids.

The acidity value was related to the presence of water in the biodiesel, since all the samples presented high values for this index. The sample purified with water showed the highest acid value and also the highest water content. The presence of water in the samples caused hydrolysis of the esters to alcohol and fatty acids, the ethyl esters being oxidized to fatty acids, thereby increasing the biodiesel acid number. Distillation produced biodiesel with an acid value within the ANP specifications. According to the literature, the observed acidity value was $0.30 \mathrm{mg} \mathrm{KOH} / \mathrm{g}$ (Rashid et al., 2008).

The iodine value of the sunflower oil used was $93.5 \mathrm{~g} / 100 \mathrm{~g}$, and the iodine values of the biodiesel samples were close to this value, as expected. According to the literature, Pereyra-Irujo et al. (2009) found iodine values for biodiesel produced from high oleic acid sunflower oil of between 81 and 88 $\mathrm{g} / 100 \mathrm{~g}$, close to the values obtained in the present work.

Free glycerol was only detected in the distilled sample, with a value above the legal specifications. Rashid et al. (2008) found $0.015 \%$ of free glycerol in the biodiesel produced from sunflower oil.

After the sunflower oil transesterification reaction, there were high concentrations of mono-, di- and triacylglycerols in the mixture. The low ethanol concentration in the reaction favored the reaction in the opposite direction to biodiesel formation. The Brazilian standards have not yet limited the levels of these components, but according to European legislation, the maximum concentrations allowed are $0.8 \%$ for mono-and
$0.2 \%$ for di-and triacylglycerols. It was to be expected that fractional distillation would properly separate the ester fraction formed from the glycerides, but this did not occur, probably due to an inadequate and inefficient distillation system.

The ester content is a measurement of the purity of biodiesel, and is related to the reaction conditions. Despite the fact that the sunflower oil transesterification did not go to completion, the three samples showed ester levels within the limits allowed by Brazilian standards.

Although the production of biodiesel from crude sunflower oil and ethanol did not meet all the criteria imposed by Brazilian standards, practical solutions can be suggested to improve the technological process used to produce and purify biodiesel in this study. The first step would be to increase the ethanol: oil molar ratio and the reaction time so as to ensure that the reaction went to completion. The biodiesel produced would thus meet the specifications regarding the glyceride content. The water content of all the biodiesel samples could be minimized by drying the samples under vacuum, also contributing to a reduction in the acidity and the use of an antioxidant would improve the oxidative stability of the biodiesel.

Of the purification techniques evaluated, distillation was considered to be the best, producing a fuel within the ANP specifications for most of the aspects evaluated. Some operational adjustments applied to the distillation system would favor system efficiency, such as the use of a more efficient condenser for cooling and a more precise temperature control.

\section{CONCLUSIONS}

The results of the experiments led to the following recommendations for the expelling of sunflower oil: rotation of $114 \mathrm{rpm}$, seed temperature of $25^{\circ} \mathrm{C}$ and seed moisture content of $7 \%$. For transesterification on a laboratory scale, the following procedure presented a high biodiesel yield: molar ratio of 9:1 and catalyst concentration of $3 \%$ by weight. When carried out in a batch reactor, the chemical reaction showed good biodiesel production, despite the fact that the amount of ethanol used was not enough to convert all the triacylglycerols into esters. Distillation was the best purification method and the final biodiesel produced was able to meet most of the technical requirements of the Brazilian biodiesel specifications.

\section{ACKNOWLEDGMENTS}

The authors acknowledge the Faculty of Agricultural Engineering (FEAGRI/UNICAMP), the Food Technology Institute (ITAL), The State of São Paulo Research Foundation (FAPESP), and The National Council for Scientific and Technological Development (CNPq) for their financial support. 


\section{REFERENCES}

American Oil Chemists Society. 2008. Official methods and recommended practices of the AOCS. Champaign: A.O.C.S.

ANP. 2010. Agência Nacional do Petróleo, Gás Natural e Biocombustíveis. <http://www.anp.gov.br>.

Association of Official Analytical Chemists. 2007. Official methods of analysis of the Association of Official Analytical Chemists. Arlington: AOAC.

Barros Neto, B. de Scarmínio, IS., Bruns, RE. 2003. Planejamento e Otimização de Experimentos. Campinas: Editora da UNICAMP.

Berrios, M. Skelton, RL. 2008. Comparison of purification methods for biodiesel. Chemical Engineering Journal 144, $459-465$.

Brossard-González, CO. Ferrari, RA., Pighinelli, ALMT., Park, KJ. 2010. Evaluación preliminary del etanol anhidro como solvente en la extracción de aceite de semillas de jatrofa (Jatropha curcas L.). Grasas y Aceites 61, 295 - 302.

Cooke, BS., Abrams, S. Bertram, B. 2003. Purification of biodiesel with adsorbent materials. US Patent 0509959P.

Domingos, AK, Saad, EB, Wilhelm, HM, Ramos, LP. 2008. Optimization of the ethanolysis of Raphanus sativus (L. Var.) crude oil applying the response surface methodology. Bioresource Technology 99, 1837 - 1845.

Domingos, A.K.; Kucek, K.T.; Wilhelm, H.M.; Ramos, L.P. 2004. Óleo bruto de girassol como matéria-prima a produção de biodiesel. In: I Congresso Brasileiro de Plantas Oleaginosas, Óleos Vegetais e Biodiesel, Lavras.

Dufaure, C., Leyris, J., Rigal, L., Mouloungui, Z. 1999. A twin-screw extruder for oil extraction: I. Direct expression of oleic sunflower seeds. Journal of American Oil Chemists Society 76, 1073 - 1079.

Ferrari, RA., Oliveira, VS., Scabio, A. 2005. Biodiesel de soja - taxa de conversão em ésteres etílicos, caracterização físico-química e consumo em gerador de energia. Química Nova 28, 19 - 23.

Georgogianni, KG., Kontominas, MG., Pomonis, PJ., Avlonitis, D. Gergis, V. 2008. Conventional and in situ transesterification of sunflower seed oil for the production of biodiesel. Fuel Processing Technology $89,503-509$.

Grace Davison. 2009. Catálogo técnico Trisyl囚. <http:// www.gracedavison.com.br>.

Jeong, G., Yang, H., Park, D. 2009. Optimization of transesterification of animal fat Ester using response surface methodology. Bioresource Technology 100, $25-30$.

Knothe, G. 2005. The history of vegetable oil-based diesel fuels, in Gerpen, JV., Knothe, G. (Eds). Biodiesel Handbook. Champaign: AOCS Press, 12 - 24.
Kucek, KT., César-Oliveira, MAF., Wilhelm, HM., Ramos, LP. 2007. Ethanolysis of refined soybean oil assisted by sodium and potassium hydroxides. Journal of the American Oil Chemist's Society 84, 385-392.

Lôbo, IP., Ferreira, SLC., Cruz, RS. 2009. Biodiesel: parâmetros de qualidade e métodos analíticos. Química Nova 32, 1596 - 1608.

Mpagalile, JJ., Hanna, MA., Weber, R. 2006. Design and testing of a solar photovoltaic operated multi-seeds oil press. Renewable Energy 31, 1855-1866.

Pereyra-Irujo, GA., Izquierdo, NG., Covi, M. Nolasco, SM., Quiroz, F., Aguirrezábal, LAN. 2009. Variability in sunflower oil quality for biodiesel production: a simulation study. Biomass \& Bioenergy 33, 459 468.

Pighinelli, ALMT., Ferrari, RA., Miguel, AMRO., Park, KJ. 2010. Different purification methods and quality of sunflower biodiesel. In XVII World Congress of the International Commission of Agricultural Engineering, Québec.

Pighinelli, ALMT. 2010. Estudo da extração mecânica e da transesterificação etílica de óleos vegetais. Tese (Doutorado em Engenharia Agrícola), Faculdade de Engenharia Agrícola, UNICAMP, Campinas, 222p.

Pighinelli, ALMT., Park, KJ., Miguel, AMRO., Oliveira, RA. 2009. Otimização da prensagem de grãos de girassol e sua caracterização. Revista Brasileira de Engenharia Agrícola e Ambiental 13, 63 - 67.

Pighinelli, ALMT., Park, KJ., Miguel, AMRO., Bevilaqua, G., Guillaumon Filho, JA. 2008. Otimização da prensagem a frio de grãos de amendoim em prensa contínua tipo expeller. Ciência e Tecnologia de Alimentos 28, 66-71.

Pighinelli, ALMT. 2007. Extração mecânica de óleos de amendoim e de girassol para produção de biodiesel via catálise básica. Dissertação (Mestrado em Engenharia Agrícola), Faculdade de Engenharia Agrícola, UNICAMP, Campinas, 94p.

Predojevic, ZJ. 2008. The production of biodiesel from waste frying oils: a comparison of different purification steps. Fuel 87, 3522 - 3528.

Rashid, U., Anwar, F., Moser, BR., Ashraj, S. 2008. Production of sunflower oil methyl esters by optimized alkali-catalyzed methanolysis. Biomass \& Bioenergy 32, $1202-1205$.

Schoenfelder, W. 2003. Determination of monoglycerides, diglycerides, triglycerides and glycerol in fats by means of gel permeation chromatography. European Journal of Lipids Science Technology 105, 45 - 48.

Statsoft. 2009. STATISTICA version 9.0. Data analysis software system. Tulsa, StatSoft, Inc.

Recibido: $24 / 6 / 10$ Aceptado: 23/9/10 